\title{
Characterization and regulation of the Resistance-Nodulation-Cell Division-type multidrug efflux pumps MdtABC and MdtUVW from the fire blight pathogen Erwinia amylovora
}

Daniel Pletzer and Helge Weingart ${ }^{*}$

\begin{abstract}
Background: The Gram-negative bacterium Erwinia amylovora is the causal agent of the devastating disease fire blight in rosaceous plants such as apple, pear, quince, raspberry, and cotoneaster. In order to survive and multiply in a host, microbes must be able to circumvent the toxic effects of antimicrobial plant compounds, such as flavonoids and tannins. E. amylovora uses multidrug efflux transporters that recognize and actively export toxic compounds out of the cells. Here, two heterotrimeric resistance-nodulation-cell division (RND)-type multidrug efflux pumps, MdtABC and MdtUWW, from E. amylovora were identified. These RND systems are unusual in that they contain two different RND proteins forming a functional pump.

Results: To find the substrate specificities of the two efflux systems, we overexpressed the transporters in a hypersensitive mutant lacking the major RND pump AcrB. Both transporters mediated resistance to several flavonoids, fusidic acid and novobiocin. Additionally, MdtABC mediated resistance towards josamycin, bile salts and silver nitrate, and MdtUWW towards clotrimazole. The ability of the mdtABC-and mdtUVW-deficient mutants to multiply in apple rootstock was reduced. Quantitative RT-PCR analyses revealed that the expression of the transporter genes was induced during infection of apple rootstock. The polyphenolic plant compound tannin, as well as the heavy metal salt tungstate was found to induce the expression of $m d t A B C$. Finally, the expression of the $m d t A B C$ genes was shown to be regulated by BaeR, the response regulator of the two-component system BaeSR, a cell envelope stress response system that controls the adaptive responses to changes in the environment.
\end{abstract}

Conclusions: The expression of MdtABC and MdtUWW is induced during growth of E. amylovora in planta. We identified the plant polyphenol tannin as inducer of mdtABC expression. The reduced ability of the mdtABC- and mdtUVW-deficient mutants to multiply in apple rootstock suggests that the efflux pumps are involved in resistance to plant antimicrobials, maybe including flavonoids, which were identified as substrates of both pumps. Furthermore, we found that the $m d t A B C$ operon belongs to the regulon of the two-component regulator BaeR suggesting a role of this RND transporter in the cell envelope stress response of E. amylovora.

Keywords: Plant pathogen, Fire blight, Erwinia amylovora, Multidrug efflux, RND transporter, MdtABC, MdtUWW, BaeR, CpxR

\footnotetext{
* Correspondence: h.weingart@jacobs-university.de

School of Engineering and Science, Jacobs University Bremen, Campus Ring

1, 28759 Bremen, Germany
} 


\section{Background}

Fire blight, caused by the Gram-negative enterobacterium Erwinia amylovora, is a devastating disease of rosaceous plants in the subfamily Maloideae that has global economic importance for apple and pear production [1]. Typical symptoms include flower necrosis, immature fruit rot, shoot curvature (shepherd's crook), blackened leaves (these generally remain attached to the plant), bacterial ooze secretion, and cankers on woody tissues.

Production of phenolic compounds with antimicrobial activity (e.g. flavonoids, tannins) is an important part of the plant defense repertoire to limit the spread of pathogens [2]. Successful phytopathogens must be able to circumvent the toxic effects of antimicrobial plant compounds. An important resistance mechanism of bacteria against plant-borne antimicrobials involves efflux of these compounds by so-called multidrug transporters. Among the transporter families containing multidrug efflux transporters, the resistance-nodulation-cell division (RND) family has been identified as the most relevant in terms of resistance to clinically important agents in Gram-negative bacteria $[3,4]$. Members of the RND family are able to recognize and expel a broad range of antimicrobials from the cell $[5,6]$. The RND-type efflux pump AcrAB has been shown to be involved in virulence of $E$. amylovora conferring resistance to plant-borne antimicrobial compounds like apple phytoalexins [7].

The functional RND-type efflux pump is a tripartite complex, consisting of the RND-type transporter protein located in the inner membrane, a periplasmic membrane protein, and an outer membrane channel [5]. The inner membrane RND transporter is a homotrimer that uses the proton gradient as an energy source [8,9]. Associated with this homotrimeric structure is the so-called 'rotating mechanism,' a conformational change in the periplasmic core domain to export drug molecules [10].

However, not all members of the RND family follow a homotrimeric organization. For example, the RNDfamily efflux system MdtABC from $E$. coli possesses two different RND transporters, MdtB and MdtC, which are co-transcribed in an operon with the membrane fusion protein MdtA. It has previously been shown that the functional pump consists of a heteromultimeric unit formed by two subunits of $\mathrm{MdtB}$ and one subunit of MdtC [11]. Furthermore, it has been suggested that MdtC is involved in binding and transport of drugs and that MdtB presumably induces the conformational change needed for transport using the proton translocation as an energy source [12].

Previous genetic studies have demonstrated that the deletion of the heteromultimeric RND pump MdtABC abolishes the resistance of E. coli and Salmonella enterica to $\beta$-lactams, novobiocin, SDS, and bile salts [13-15]. Moreover, MdtABC has been implicated in detoxification of heavy metals, in particular, in resistance to zinc, copper and tungstate [15-17].

In E. coli, the expression of the multidrug efflux pump $\mathrm{Mdt} A B C$ is regulated by two stress response systems, Bae and Cpx. The BaeSR and CpxARP two-component signal transduction systems respond to damage of the cell envelope; however, they differ with regard to specific inducers. The BaeSR regulon responds to a wide range of environmental stresses, including spheroplast formation, overexpression of the PapG pilin under conditions leading to misfolding, and exposure to indole, tannins, flavonoids, tungstate, and zinc [16,18-20]. The small core regulon of BaeSR includes the BaeSR two-component system itself, the RND-type transporters AcrD and MdtABC, and the periplasmic chaperone Spy [19]. The CpxRA regulon of E. coli contains hundreds of genes, including periplasmic protein folding and degrading factors, peptidoglycan metabolic enzymes, inner membrane proteins and regulators, and envelope-localized protein complexes, such as pili and flagella [21-23]. The Cpx system comprises the sensor histidine kinase CpxA, the cytoplasmic response regulator $\mathrm{CpxR}$, and $\mathrm{CpxP}$, a periplasmic inhibitor of CpxA [24]. The Cpx pathway is activated by a variety of stresses within the bacterial cell envelope, e.g., alkaline $\mathrm{pH}$, alterations to the composition of the inner membrane, overexpression of misfolded envelope proteins, and adhesion to hydrophobic surfaces sensed by the lipoprotein NlpE [23,25]. Hirakawa et al. [26] reported that the overexpression of BaeR and CpxR causes up-regulation of RND pumps AcrD and MdtABC in E. coli. Analysis of the induction of multidrug transporter genes by indole revealed that the CpxR-mediated induction of $a c r D$ and $m d t A B C$ genes depends on the BaeSR two-component system [27]. These results indicate that BaeR is a primary regulator, and CpxR enhances the effect of BaeR.

The aim of this study was to characterize the heteromultimeric RND-type multidrug efflux pumps MdtABC and MdtUVW from E. amylovora Ea1189 and to determine the role of the two-component system regulators BaeR and CpxR in regulation of these efflux systems.

\section{Results}

\section{Computational analysis of RND-type transporters from E. amylovora Ea1189}

Analysis of the genome sequence of E. amylovora revealed the presence of two, hitherto not characterized, operons encoding heterotrimer-type RND-type efflux pumps. Both show homology to the $m d t A B C$ operon of $E$. coli. The $m d t A B C$ genes of $E$. coli encode an RND system that is unusual in that it contains two different RND pump genes, $m d t B$ and $m d t C$, in addition to the membrane fusion protein gene, $m d t A$ [11]. One of the heterotrimertype RND efflux systems of $E$. amylovora shows a high degree of homology to the E. coli MdtABC transporter as 
depicted in the phylogenetic tree in Figure 1. We accordingly propose to name the operon encoding this transporter as $m d t A B C$. The second, more distantly related operon was named mdtUVW.

A sequence alignment showed that the RND pump MdtB from E. amylovora Ea1189 shares 59\% identity with $\mathrm{MdtV}$ and $81 \%$ identity with MdtB from E. coli (Additional file 1). MdtV shares only $61 \%$ identity with MdtB from E. coli. The RND pump MdtC from E. amylovora shares $54 \%$ identity with MdtW and $74 \%$ identity with MdtC from E. coli. MdtW shares $56 \%$ identity with MdtC from E. coli. Furthermore, E. coli possesses an additional gene, ice $T$ (formerly known as $m d t D$ ), encoding an iron citrate efflux transporter of the major facilitator superfamily, within the $m d t A B C$ operon [30]. No homologue of the iceT is present in the genome of $E$. amylovora.

Analysis of the up- and downstream regions flanking the mdtABC operons from E. amylovora and $E$. coli revealed the presence of the baeSR genes located downstream of the $m d t A B C$ operons in both organisms (Additional file 2). The two-component system
BaeSR is involved in a unique envelope stress response in E. coli $[18]$.

Topological analysis of the RND proteins MdtB, MdtC, MdtV, and MdtW from E. amylovora using the TOPCONS software [31] predicted 12 transmembranespanning domains (TMDs) and two large periplasmic loops between TMD 1 and 2 and TMD 7 and 8 for all four transporters (Additional file 3). This transmembrane organization is typical for members of the RND family $[32,33]$.

\section{Phenotypic characterization of the $m d t A B C$ and $m d t U V W$ mutants}

In order to investigate the role of the RND-type multidrug efflux pumps MdtABC and MdtUVW in antibiotic resistance and to identify pump-specific substrates, antimicrobial susceptibility tests of the wild type and the corresponding mutants were performed. However, deletion of the $m d t A B C$ and $m d t U V W$ operon, respectively, resulted in no changes in sensitivity to all tested antimicrobial agents including plant-derived antimicrobials, antibiotics, dyes, and heavy metals (Table 1).

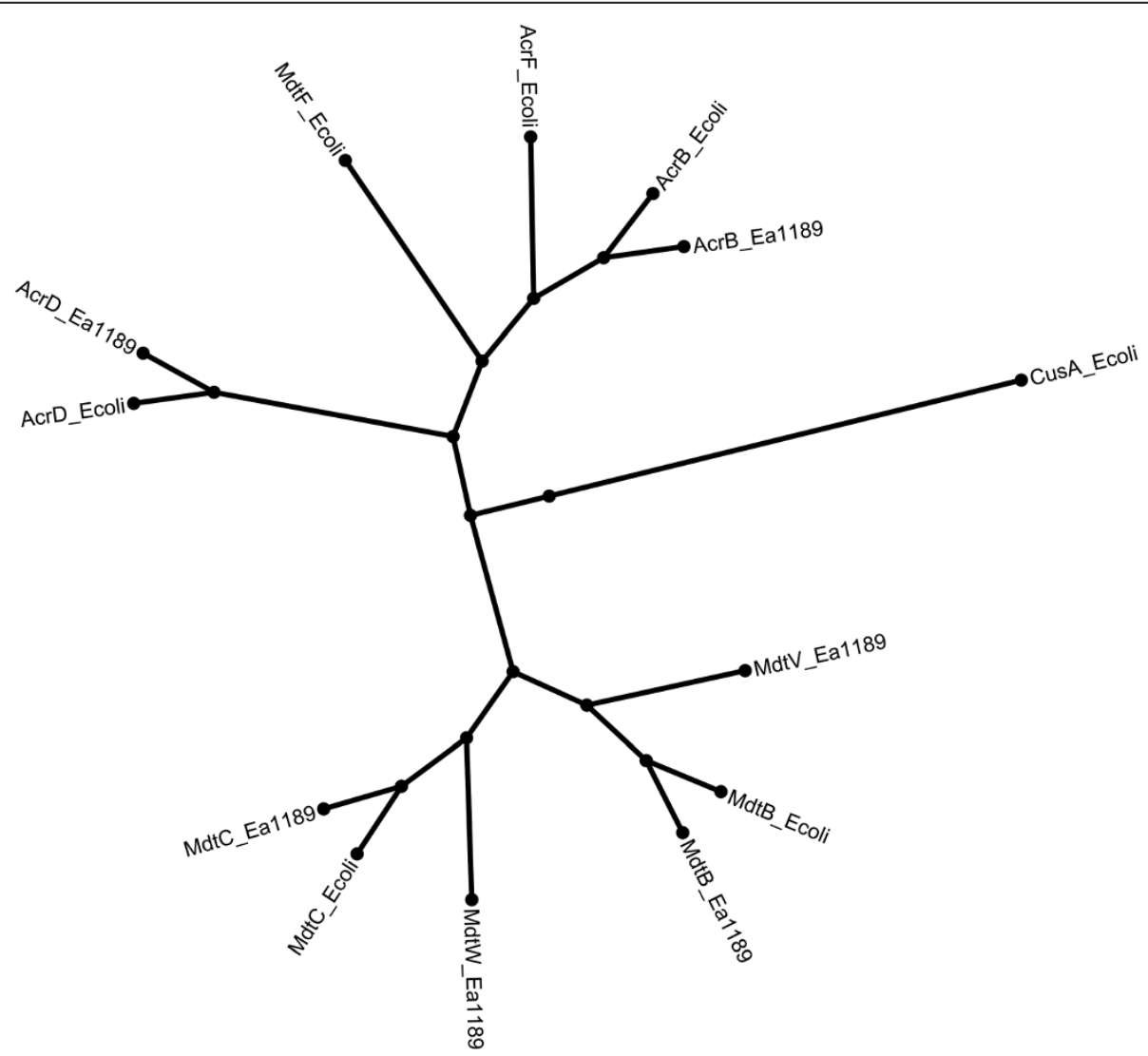

Figure 1 Phylogenetic tree of the RND transporters AcrB, AcrF, AcrD, CusA, MdtF, MdtB, and MdtC from E. coli MG1655 and AcrB, AcrD, MdtB, MdtC, MdtV and MdtW from E. amylovora Ea1189. Multiple sequence alignment was performed using Clustal Omega [28] and the result visualized by FigTree [29]. 
Table 1 Antimicrobial susceptibility profiles

\begin{tabular}{|c|c|c|c|c|c|c|}
\hline \multirow[t]{2}{*}{ Drug } & \multicolumn{6}{|c|}{$\mathrm{MIC}(\mu \mathrm{g} / \mathrm{ml})^{\mathrm{a}}$} \\
\hline & Ea1189 & 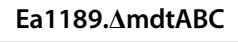 & 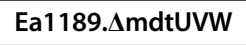 & Ea1189-3 & Ea1189-3 pBlueSK.mdtABC & Ea1189-3 pBlueKS.mdtUVW \\
\hline \multicolumn{7}{|l|}{ Phytochemicals } \\
\hline Apple extract & $>100000$ & $>100000$ & $>100000$ & 25000 & 50000 & 25000 \\
\hline Tannin & 625 & 625 & 625 & 1250 & 5000 & 1250 \\
\hline \multicolumn{7}{|l|}{ Flavones } \\
\hline Apigenin & $>2500$ & $>2500$ & $>2500$ & 31.2 & 125 & $>1000$ \\
\hline Daidzein & 1000 & 1000 & 1000 & 156 & 1000 & 1000 \\
\hline Genistein & $>1000$ & $>1000$ & $>1000$ & 62.5 & 125 & $>1000$ \\
\hline Kaempferol & $>5000$ & $>5000$ & $>5000$ & 250 & 1000 & 1000 \\
\hline Luteolin & $>1000$ & $>1000$ & $>1000$ & 12.5 & 25 & $>100$ \\
\hline Myricetin & 2500 & 2500 & 2500 & 1250 & 1250 & 1250 \\
\hline Naringenin & 1000 & 1000 & 1000 & 250 & 250 & 1000 \\
\hline Quercitin & 5000 & 5000 & 5000 & 2500 & 2500 & 5000 \\
\hline Orobol & 1000 & 1000 & 1000 & 31.2 & 31.2 & 1000 \\
\hline \multicolumn{7}{|l|}{$\beta$-Lactams } \\
\hline Ampicillin & 312 & 312 & 312 & 25 & 50 & 50 \\
\hline Carbenicillin & 312 & 312 & 312 & 50 & 50 & 50 \\
\hline Cefepime & 12.5 & 12.5 & 12.5 & 0.16 & 0.31 & 0.16 \\
\hline Cefoxitin & 62.5 & 62.5 & 62.5 & 25 & 25 & 25 \\
\hline Cefsulodin & 156 & 156 & 156 & 50 & 50 & 50 \\
\hline Ceftazidime & 1000 & 1000 & 1000 & 6.2 & 6.2 & 6.2 \\
\hline Cloxacillin & 2500 & 2500 & 2500 & 25 & 25 & 25 \\
\hline Oxacillin & 1250 & 1250 & 1250 & 12.5 & 25 & 25 \\
\hline Ticarcillin & 250 & 250 & 250 & 50 & 50 & 50 \\
\hline \multicolumn{7}{|l|}{ Aminoglycosides } \\
\hline Amikacin & 3.1 & 3.1 & 3.1 & 5 & 5 & 5 \\
\hline Gentamicin & 2.5 & 2.5 & 2.5 & 2.5 & 2.5 & 2.5 \\
\hline Kanamycin & 6.2 & 6.2 & 6.2 & $>100$ & $>100$ & $>100$ \\
\hline Neomycin & 3.1 & 3.1 & 3.1 & $>100$ & $>100$ & $>100$ \\
\hline Streptomycin & 3.1 & 3.1 & 3.1 & 5 & 5 & 5 \\
\hline Tobramycin & 1.2 & 1.2 & 1.2 & 5 & 5 & 5 \\
\hline \multicolumn{7}{|l|}{ Antibiotics } \\
\hline Chloramphenicol & 3.1 & 3.1 & 3.1 & 1.5 & 1.5 & 1.5 \\
\hline Erythromycin & 1.2 & 1.2 & 1.2 & 0.3 & 0.3 & 0.6 \\
\hline Fosfomycin & 1250 & 1250 & 1250 & 156 & 312 & 156 \\
\hline Fusidic acid & 250 & 250 & 250 & 6.2 & 62.5 & 100 \\
\hline Josamycin & 250 & 250 & 250 & 6.2 & 50 & 12.5 \\
\hline Lincomycin & 1250 & 1250 & 1250 & 78 & 78 & 78 \\
\hline Norfloxacin & 0.13 & 0.13 & 0.13 & 0.03 & 0.03 & 0.06 \\
\hline Novobiocin & 125 & 125 & 125 & 6.2 & 100 & 100 \\
\hline Rifampicin & 50 & 50 & 50 & 31.2 & 31.2 & 50 \\
\hline Tetracycline & 2.5 & 2.5 & 2.5 & 0.63 & 1.25 & 1.25 \\
\hline Trimethoprim & 625 & 625 & 625 & 625 & 625 & 625 \\
\hline
\end{tabular}


Table 1 Antimicrobial susceptibility profiles (Continued)

\begin{tabular}{|c|c|c|c|c|c|c|}
\hline \multicolumn{7}{|l|}{ Dyes } \\
\hline Acriflavine & 31.2 & 31.2 & 31.2 & 25 & 25 & 25 \\
\hline Ethidium bromide & 500 & 500 & 500 & 6.2 & 6.2 & 6.2 \\
\hline \multicolumn{7}{|l|}{ Antimicrobials } \\
\hline Bile & 5000 & 5000 & 5000 & 625 & 2500 & 1250 \\
\hline Clotrimazole & $>1000$ & $>1000$ & $>1000$ & 6.2 & 6.2 & $>100$ \\
\hline Indole & 625 & 625 & 625 & 625 & 625 & 625 \\
\hline SDS & 625 & 625 & 625 & 125 & 125 & 250 \\
\hline \multicolumn{7}{|l|}{ Heavy metals } \\
\hline Cadmium acetate & 25 & 25 & 25 & 25 & 25 & 25 \\
\hline Copper sulfate & 1250 & 1250 & 1250 & 1250 & 1250 & 1250 \\
\hline Silver nitrate & 6.2 & 6.2 & 6.2 & 6.2 & 25 & 6.25 \\
\hline Sodium tungstate & 125000 & 125000 & 125000 & 62500 & 62500 & 62500 \\
\hline Zinc sulfate & 312 & 312 & 312 & 312 & 625 & 312 \\
\hline
\end{tabular}

${ }^{\mathrm{a}} \mathrm{MIC}$ values were determined by the 2 -fold dilution assay in three or more independent experiments with similar results. Boldface numbers indicate a more than 2-fold higher MIC. ND, not determined.

MIC values were determined from an E. amylovora wild-type strain, mdtABC mutant, and mdtUVW mutant, as well as from an acrB mutant Ea1189-3 complemented with MdtABC-overexpression plasmid pBlueSK.mdtABC or MdtUVW-overexpression plasmid pBlueKS.mdtUVW-ext.

\section{Effect of $m d t A B C$ and $m d t U V W$ overexpression on multidrug resistance in an $a c r B$-deficient mutant of E. amylovora}

Since disruption of the $m d t A B C$ and $m d t U V W$ operons did not cause hypersusceptibility to any of the tested compounds, possibly due to their low expression during cellular growth or due to the activity of the highly expressed AcrAB efflux pump, overexpression of the $m d t A B C$ and $m d t U V W$ operons from high-copy plasmids in an $a c r B-$ deficient mutant was achieved. Different plasmids expressing the RND operons under control of three different promoters were generated: lac promoter $\left(\mathrm{P}_{\text {lac }}\right)$, native promoter $\left(\mathrm{P}_{\text {mdtABC }}\right.$ or $\left.\mathrm{P}_{\text {mdtUVw }}\right)$, and dual promoter (lac promoter and native promoter). To investigate the role of the RND pumps in $\beta$-lactam resistance, the bla gene of the high-copy plasmid pBlueScript II $\mathrm{KS}(+)$ and pBlueScript II SK(+) used for overexpression of the $m d t A B C$ and $m d t U V W$ operons was replaced by a $\mathrm{Sm} / \mathrm{Sp}$ resistance cassette (Additional file 4). All constructs were mobilized into the acrB-deficient mutant Ea1189-3 and the sensitivity of the transformants to various substrates was determined (Table 1).

Our initial data indicated that expression of the RND operons from different promoters had a strong influence on the MIC values. Therefore, we utilized qRT-PCR to analyze the mRNA expression from the different constructs and found that the expression of the $m d t A B C$ operon driven by $\mathrm{P}_{\text {lac }}$ (40-fold) was 10 times higher than the expression driven by the dual promoter (4-fold). Interestingly, there was almost no increased expression of the $m d t A B C$ operon from its native promoter (2-fold). Although we detected minor MIC changes after expression of the $m d t A B C$ operon from its native promoter and dual promoter, respectively, expression driven by $\mathrm{P}_{\text {lac }}$ resulted in the highest changes in MIC values. In contrast, the expression levels of the mdtUVW operon from $\mathrm{P}_{\text {lac }}$ or from its native promoter were similar low (2- to 4-fold). The expression of the mdtUVW operon from the dual promoter was much higher (18-fold), however, did not result in MIC changes. Interestingly, only with the expression from the native promoter, we were able to detect minor changes in MIC values.

The expression of $m d t A B C$ from a high-copy vector under the control of the lac promoter, in an $a c r B$-deficient mutant, resulted in increased resistance to tannin (4-fold), apigenin (4-fold), daidzein (8-fold), kaempferol (4-fold), fusidic acid (8-fold), josamycin (8-fold), novobiocin (16fold), bile salts (4-fold) and silver nitrate (4-fold) (Table 1). The expression of $m d t U V W$ from a high-copy vector under the control of its native promoter increased the MICs of several flavonoids including apigenin ( $>32$ fold), daidzein (8-fold), genistein ( $>16$-fold), kaempferol (4-fold), luteolin (>8-fold), naringenin (4-fold), and orobol (32-fold), and of the antibiotics fusidic acid (16-fold), novobiocin (16-fold) and clotrimazole (>16-fold) (Table 1).

\section{RND-type efflux pump expression during cellular growth}

The relative mRNA transcript abundance of $m d t A$ and mdtU from E. amylovora Ea1189 during cellular growth was determined by quantitative RT-PCR. Therefore, total RNA was isolated at distinct optical densities $\left(\mathrm{OD}_{600}\right.$ of $0.5,1.0,1.5$ and 2.0) and the expression normalized to the highest expression of each transcript. The mRNA transcript levels of $m d t A$ and $m d t U$ were constant but 
low during growth in LB medium as determined by $C_{t}$ values (Additional file 5). Analysis of transcriptional fusions between the promoter regions of the efflux pumps and the reporter gene egfp supported these results. Fluorescence measurements showed that the activity of the $m d t A B C$ and $m d t U V W$ promoters were 3- to 5-fold lower than the activity of the acrA promoter throughout growth in LB broth.

\section{Effect of substrate exposure on mdtABC and mdtUVW expression}

To investigate whether antimicrobials effect the expression of $m d t A B C$ or $m d t U V W$ in E. amylovora, transcriptional fusions between the $m d t A B C$ upstream region and $m d t U V W$ upstream region, respectively, to the egfp gene were constructed, yielding plasmids pBBR.mdtABC-Pro. egfp and pBBR.mdtUVW-Pro.egfp.

Antimicrobial compounds were added to the plasmidharboring cells by the 2-fold dilution method in 96-well plates and EGFP fluorescence was determined after 24 hours. Only fluorescence values from substrate concentrations that did not inhibit bacterial growth were considered. Potential inducers of gene expression (49 compounds have been tested), showing higher fluorescence than the remaining dataset, were identified as fusaric acid for the $m d t A B C$ promoter and copper sulphate for the $m d t U V W$ promoter (data not shown).

In addition, we analyzed the expression of $m d t A$ and $m d t U$ by qRT-PCR after 2 hours induction with several antimicrobials. Tested compounds were phloretin, naringenin, mycricetin, methanolic and acetonic apple extract, indole, paraquat, phenolic acids, gallic acid, tannin, indole-3-acetic acid, and the metals iron, copper, zinc, and tungstate. Our data showed an induction of $m d t A$ by tannin (4.4-fold) and tungstate (2.4-fold), while expression of $m d t U$ was not induced by the tested compounds (Table 2). Furthermore, we observed that the regulatory gene baeS was 2.8 -fold induced by tannin (data not shown).

\section{Regulation of the RND-type pumps MdtABC and MdtUVW in E. amylovora}

Several studies suggest a connection between cell envelope stress responses and expression of multidrug efflux systems. In $E$. coli, the two-component signal transduction systems BaeSR and CpxARP respond to damage of the cell envelope and have been shown to regulate the expression of drug exporter genes including the RND efflux pump MdtABC [13,14,27]. Since a BLAST search revealed the presence of homologous systems in the genome sequence of E. amylovora (Additional file 6), it prompted us to investigate whether the response regulators BaeR and CpxR control expression of the MdtABC and MdtUVW transporters in E. amylovora Ea1189.
Table 2 Relative fold-changes of $\boldsymbol{m d t} A$ and $\boldsymbol{m d t} U$ mRNA transcripts in E. amylovora Ea1189 after $2 \mathrm{~h}$ of incubation with transporter substrates as determined by qRT-PCR $^{a}$

\begin{tabular}{|c|c|c|}
\hline & $m d t A^{b}$ & mdtU \\
\hline Methanolic apple extract $(1 \mu \mathrm{l} / \mathrm{ml})$ & 1.2 & 1.2 \\
\hline Acetonic apple extract $(10 \mu \mathrm{l} / \mathrm{ml})$ & 1.2 & 1.5 \\
\hline Tannin $(0.5 \mathrm{mg} / \mathrm{ml})$ & 4.4 & 1.7 \\
\hline Phloretin (4 ㅆg/ml) & 0.8 & 0.9 \\
\hline Naringenin $(8 \mu \mathrm{g} / \mathrm{ml})$ & 1.1 & 1.1 \\
\hline Myricetin $(10$ mg/ml) & 0.8 & 0.7 \\
\hline Indole (2 mM) & 1.0 & 0.7 \\
\hline Paraquat (0.2 mM) & 0.9 & 1.3 \\
\hline Phenolic acids ${ }^{c}$ (0.078 mM) & 0.9 & 0.7 \\
\hline Gallic acid (1 mg/ml) & 1.4 & 1.5 \\
\hline Indole-3-acetic acid (2 mM) & 0.8 & 0.7 \\
\hline Iron sulphate (1 mM) & 0.9 & 0.8 \\
\hline Copper sulphate (1 mM) & 1.1 & 1.4 \\
\hline Zinc sulphate (1 mM) & 1.1 & 1.4 \\
\hline Sodium Tungstate (20 mM) & 2.4 & 1.2 \\
\hline
\end{tabular}

${ }^{a}$ Total RNA was isolated from bacterial cells incubated for 2 hours with transporter substrates in LB broth. Transcript abundance was determined by quantitative RT-PCR and compared to RT-PCR signal from cells grown in LB broth containing only the solvent of the respective substrate.

${ }^{b}$ Boldface values indicate an increase of at least 2-fold. Represented data values are the means of at least three replicates.

${ }^{c} \mathrm{~A}$ mixture of $0.078 \mathrm{mM}$ salicylic acid and $0.078 \mathrm{mM}$ benzoic acid was used.

To test whether BaeR or CpxR bind to the promoter regions of $m d t A B C$ or $m d t U V W$ in vitro, an electrophoretic mobility shift assay (EMSA) was performed. DNA fragments used in the EMSA were the Cy5-labeled upstream regions of $m d t A B C$ (290 bp), $m d t U V W(276 \mathrm{bp})$ and as control, a fragment located within the tolC gene (248 bp). The DNA fragments were incubated with increasing amounts of purified BaeR or CpxR protein in the presence of nonspecific competitor DNA (Salmon sperm) (Figure 2). The purified BaeR protein showed binding to the upstream region of $m d t A B C$ with increasing concentrations (Figure 2A). However, no interaction between BaeR and the mdtUVW promoter region was observed. Furthermore, no interaction between CpxR and the $m d t A B C$ or $m d t U V W$ promoter region was detected. In vitro phosphorylation of the purified protein using acetyl phosphate did not lead to a binding of CpxR to one of the DNA fragments. Phosphorylation of BaeR enhanced the binding to the $m d t A B C$ promoter region about 2-fold.

\section{Induction of $m d t A B C$ and $m d t U V W$ expression by the response regulators $B a e R$ and $C p x R$}

Owing to the interaction between the $m d t A B C$ promoter region and BaeR in the EMSA, we investigated whether overexpression of BaeR and CpxR may induce the expression of efflux pump genes in vivo. Therefore, baeR 


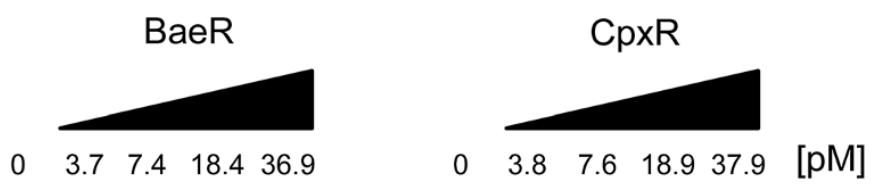

A

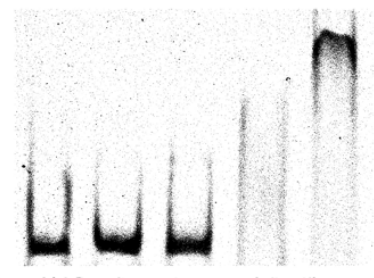

B
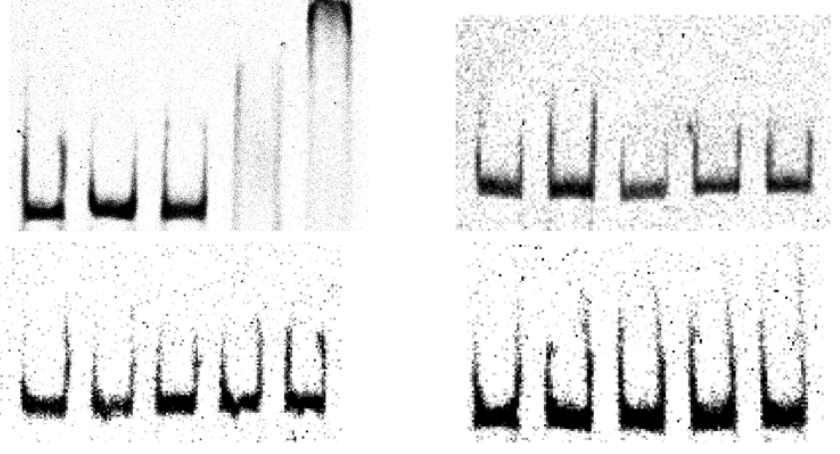

C
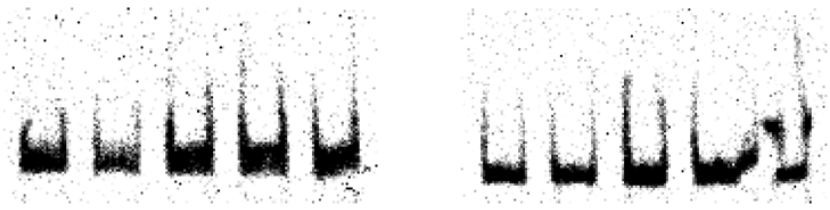

Figure 2 Electrophoretic mobility shift analysis of BaeR and CpxR interaction with Cy5-labeled DNA fragments. DNA fragments contain the promoter regions of (A) $m d t A B C(290$ bp), (B) $m d t U V W(276$ bp) and (C) a fragment from within the to/C gene (248 bp) as control. Approximately $0.3 \mathrm{pmol}$ of the DNA fragments were incubated with increasing amounts of His-tag purified BaeR and CpxR, respectively (indicated at the top of the panel). The DNA-protein complexes were separated on $4 \%$ non-denaturing polyacrylamide gels.

and $\operatorname{cpxR}$ were cloned under control of an arabinoseinducible promoter into plasmid pBAD24 and the constructs were mobilized into Ea1189 wild-type cells. Analysis of the expression levels using qRT-PCR identified a 13-fold induction of baeR and a 49-fold induction of $c p x R$ in Ea1189 cells harboring the respective plasmids (Table 3). We have previously reported that overexpression of BaeR induces the expression of the RND pump gene acrD about 4-fold, while the expression of acrA and tolC was not affected [34]. In this study we found that overexpression of BaeR increased the expression of $m d t A B C$

Table 3 Relative fold-changes of mRNA transcripts of RND-type efflux pumps and the outer membrane protein TolC in E. amylovora Ea1189 harboring plasmids pBAD.baeR and pBAD.cpxR, respectively ${ }^{a}$

\begin{tabular}{|c|c|c|c|c|c|c|c|}
\hline & acrA & $a c r D^{b}$ & $m d t A$ & $m d t U$ & tolC & baeR & $c p \times R$ \\
\hline pBAD.baeR & 0.8 & 3.8 & 20.5 & 0.8 & 0.7 & 13.3 & 0.9 \\
\hline pBAD.cpxR & 1.2 & 1.5 & 0.9 & 0.9 & 1.2 & 0.9 & 49.0 \\
\hline
\end{tabular}

${ }^{a}$ Total RNA was isolated from bacterial cells grown in LB broth at $28^{\circ} \mathrm{C}$ and induced with $1 \% \mathrm{~L}$-arabinose for 1 hour. Transcript abundance was determined by quantitative RT-PCR and compared to RT-PCR signal of uninduced cultures.

${ }^{b}$ Boldface values indicate an increase of at least 2-fold. Represented data values are the means of at least three replicates. more than 20-fold (Table 3). However, no induction of the MdtUVW pump was observed. The qRT-PCR results correlate well with the observed interaction of BaeR in the EMSA, indicating a specific binding of BaeR to the promoter region of $m d t A B C$.

In contrast, overexpression of the CpxR response regulator did not alter the expression of any multidrug efflux pump gene in E. amylovora (Table 3).

\section{Transcriptional analysis of $m d t A$ and $m d t U$ in planta}

In order to analyze the expression of $m d t A$ and $m d t U$ in planta, Ea1189 was inoculated into shoot tips of apple rootstocks MM106 as well as onto immature pear fruit slices. Bacteria were re-isolated from immature pear fruit slices 12 hours after inoculation and 1, 3 and 7 days, respectively, after inoculation from apple shoot tips. Infected plant tissue was macerated and total RNA isolated from recovered cells to determine the transcript abundances of $m d t A$ and $m d t U$ by quantitative RT-PCR. RT-PCR signals of recovered bacteria were compared with RT-PCR signals of Ea1189 cells grown in LB broth to an $\mathrm{OD}_{600}$ of 0.5 (Table 4). Analysis of relative fold changes in mRNA transcripts showed that the expression of $m d t A$ and $m d t U$ increased 1.8- and 1.7-fold, respectively, on immature pear 
Table 4 Relative fold-changes of $m d t A, m d t U$, baeS and CPXR mRNA transcripts after inoculation of $E$. amylovora Ea1189 on apple rootstocks MM106 and immature pear fruit slices, respectively ${ }^{a}$

\begin{tabular}{lllll}
\hline Gene & \multicolumn{2}{l}{ Apple rootstock } & Immature pear \\
\hline & $1 \mathrm{dpi}^{b}$ & $4 \mathrm{dpi}$ & $7 \mathrm{dpi}$ & $12 \mathrm{hpi}^{\mathrm{c}}$ \\
$m d t A$ & $\mathbf{5 8 . 7 ^ { d }}$ & $\mathbf{3 6 . 7}$ & $\mathbf{5 4 . 2}$ & 1.7 \\
$m d t U$ & $\mathbf{2 . 6}$ & $\mathbf{3 . 4}$ & 1.4 & 1.8 \\
\hline
\end{tabular}

${ }^{a}$ Total RNA was isolated from bacterial cells recovered from infected plant tissues. Transcript abundance was determined by quantitative RT-PCR and compared to RT-PCR signals from cells grown in LB broth to an $\mathrm{OD}_{600}$ of 0.5 . ${ }^{b}$ Bacteria were re-isolated from infected shoots of apple rootstock 1, 4 and 7 days post inoculation (dpi).

${ }^{c}$ Bacteria were re-isolated from infected immature pears 12 hours post inoculation (hpi).

${ }^{d}$ Boldface values indicate an increase of at least 2 -fold.

fruits. Our results further demonstrate that expression of $m d t A$ was high throughout the seven monitored days (37to 59-fold increased when compared to data obtained from growth in LB medium), which might also be due to the very low expression in LB broth during the cell cycle. In connection with the $m d t A$ expression, the $m d t U$ expression was about 3-fold induced within the first three days after infection of apple rootstock and returned to the base level after seven days.

\section{Virulence of $E$. amylovora efflux pump mutants on apple} rootstocks and immature pear fruits

Apple rootstocks MM106 were used to monitor the development of disease symptoms after infection with $E$. amylovora Ea1189 and corresponding RND-type efflux pump

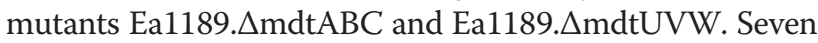
days after infection all injected shoots showed typical disease symptoms including the shepherd's crook-like bending, tissue necrosis and ooze formation. In order to study the establishment of bacterial populations within the tissue, samples were taken 1, 3 and 7 day(s) post inoculation and CFUs per stem determined. Three days after inoculation the wild type and the mutants showed similar growth. However, after seven days the population size of the $m d t A B C$ and $m d t U V W$ mutant was 5- and 10times lower, respectively, than the population size of the wild type. These results indicate that both RND-type pumps contribute to the ability of E. amylovora to survive and multiply in apple rootstock MM106 (Figure 3, Additional file 7).

Since E. amylovora is also able to infect pears, we used immature pear fruits to study the impact of the RNDpumps AcrB, MdtABC and MdtUVW on virulence. Fruits were infected with the wild type and the mutants and incubated at $28^{\circ} \mathrm{C}$ for 6 days and at $18^{\circ} \mathrm{C}$ for 14 days. However, except for the $a c r B$ mutant, no differences between the wild type and the mutants were observed (Additional file 8).

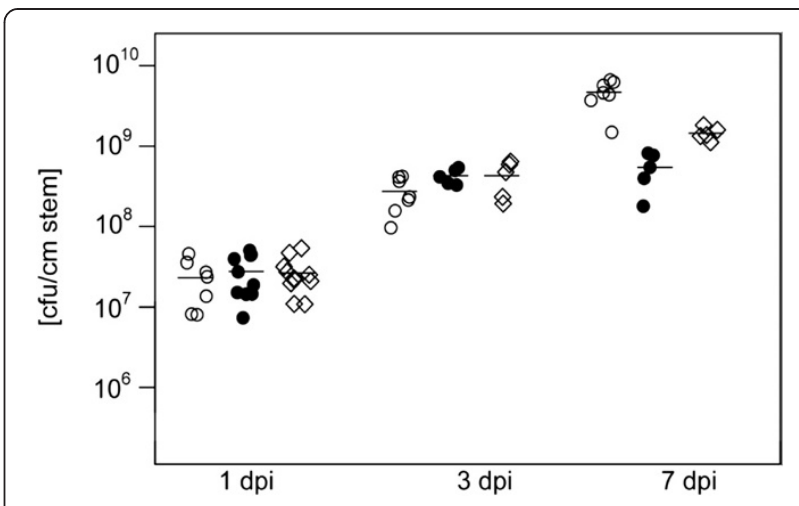

Figure 3 Virulence assay on apple rootstock MM106. Bacteria were inoculated by prick technique in the shoot tips with an inoculum of $5 \times 10^{6} \mathrm{CFU} /$ shoot. Establishment of a population of $E$. amylovora Ea1189 wild type (o), mdtUVW-deficient mutant (•) and mdtABC-deficient mutant $(\diamond)$ was determined 1, 3 and 7 days post inoculation (dpi), respectively. A minimum of 5 plant shoot tips were inoculated. Data points represent the CFU/Cm stem per shoot tip. The horizontal line through the points of a dataset indicates the mean value of the replicates. Average values and standard deviations are listed in Additional file 7

\section{Discussion}

The highly virulent plant pathogen E. amylovora Ea1189 possesses four RND-type multidrug efflux transporters: AcrAB, AcrD, MdtABC, and MdtUVW. AcrAB has previously been shown to be involved in resistance against a broad range of structurally unrelated compounds including plant-borne antimicrobials [7]. AcrD has been characterized as efflux transporter conferring resistance to a limited number of amphiphilic compounds [34]. The RND transporter AcrB and AcrD exist as homotrimers in the inner membrane and conduct drug transport by the functionally rotating mechanism [35]. The genome sequence of $E$. amylovora contains two additional operons encoding RND-type efflux transporters, $m d t A B C$ and $m d t U V W$, with homology to the MdtABC transporter from $E$. coli. The heterotrimeric $\mathrm{MdtB}_{2} \mathrm{C}$ complex is the functional form of the $E$. coli transporter. MdtC is likely involved in substrate binding and transport, whereas the two copies of $\mathrm{MdtB}$ use proton translocation as energy source to induce the conformational change needed for drug transport [12]. This work aimed to characterize the heterotrimeric RND transporters MdtABC and MdtUVW from E. amylovora Ea1189, analyze the regulation of their expression, and identify their role in virulence.

Since deletion of the $m d t A B C$ or $m d t U V W$ operon did not alter the cellular drug resistance profile of the respective E. amylovora mutants (Table 1), we overexpressed the efflux operons in the E. amylovora mutant Ea1189-3 defective in the major multidrug efflux pump AcrB. Overexpression of the MdtABC transporter in E. amylovora Ea1189-3 led to increased resistance towards three 
flavonoids (apigenin, daidzein, kaempferol), tannin, fusidic acid, josamycin, novobiocin, bile salts and silver nitrate. On the other hand, overexpression of the MdtUVW transporter led to increased resistance towards several flavonoids (apigenin, daidzein, genistein, kaempferol, luteolin, naringenin, orobol), fusidic acid, novobiocin and clotrimazole. Additionally, we observed a slight increase in resistance of the MdtABC-overexpressing strain towards acetonic apple leaf extracts (Table 1). The MdtABC and MdtUVW pumps from E. amylovora share overlapping substrate specificities with the MdtABC pumps from $E$. coli and S. enterica $[13,19,36]$. Shared substrates are novobiocin, bile salts and flavonoids suggesting that these compounds may resemble the natural substrates of the pumps.

The intrinsic resistance of $E$. amylovora towards flavonoids and tannin, mediated by the efflux pumps MdtABC and MdtUVW, is interesting since an increased production of polyphenols has been identified as defense mechanism of plants against fungal and bacterial infections $[37,38]$. Flavonoids occur widely in plants, are biologically important and are chemically diverse groups of secondary metabolites that possess a wide range of biological activities, including defense against pathogens [37]. Inducible biosynthesis of 3-deoxyflavonoid has been demonstrated to be accompanied by increased resistance of apple and pear leaves to fire blight infections [39]. To survive and multiply in its host plants, E. amylovora must be able to circumvent the toxic effect of these antimicrobial phytoalexins. We have previously demonstrated that the RNDtype transporter AcrAB is involved in resistance toward apple phytoalexins and that it is required for successful colonization of the host plant [7]. Mutation of $a \mathrm{crB}$ in $E$. amylovora dramatically reduced tolerance to apple phytoalexins phloretin, naringenin, quercetin, and (+)-catechin. Herein, we report that the RND-type efflux transporters MdtABC and MdtUVW are also involved in secretion of antibacterial plant polyphenols, such as flavonoids and tannin. Furthermore, inactivation of the RND-type pumps MdtABC and MdtUVW, respectively, resulted in a reduced ability of E. amylovora to survive and multiply within apple rootstock MM106 (Figure 3). The population size of the $m d t A B C$ mutant was 3-fold lower than the population size of the wild type seven days after infection. The mdtUVW mutant showed an even greater reduction in its ability to multiply within apple rootstock reaching a 10-fold lower population size. In several bacterial pathosystems, virulence factors are induced by plant-derived signals. Expression analysis by qRT-PCR revealed an about 3 -fold induction of the $m d t U$ gene in the early infection phase from day 1 to 3 after infection of apple tissue with E. amylovora (Table 4). In contrast, the $m d t A$ gene showed an about 50-fold increase in transcript abundance during growth of E. amylovora in apple rootstock. We identified tannin as an inducer of $m d t A$ expression and as substrate of the MdtABC transporter (Tables 1 and 2). Condensed tannins, also called proanthocyanidins, are polymers formed by the condensation of flavonoids [40]. It has previously been demonstrated that the multidrug transporter MdtABC from E. coli was upregulated in the presence of Acacia mearnsii tannin extract [20]. In addition to MdtABC, condensed tannins induced also other members of the envelope stress response regulated by the BaeSR two-component system in E. coli [20]. Indeed, the baeSR operon was also found to be up-regulated (2.8-fold) in E. amylovora during growth in medium containing tannin (data not shown). The response regulator BaeR was shown to positively regulate the expression of the $m d t A B C D$ locus in $E$. coli and $S$. enterica, leading to increased resistance to novobiocin, deoxycholate, SDS and $\beta$-lactam antibiotics $[14,15,26,41]$.

The response regulator BaeR was shown to bind to the promoter region of the $m d t A B C D$ locus in $E$. coli and $S$. enterica $[14,15]$. In this study, we investigated whether BaeR is able to bind to the promoter regions of $m d t A B C$ and $m d t U V W$ in E. amylovora. Our results show that BaeR binds to the promoter region of $m d t A B C$ but not to the $m d t U V W$ promoter (Figure 2). Furthermore, overexpression of BaeR induced the expression of the RNDtype efflux pumps acrD and $m d t A B C$ (Table 3 ).

Another envelope stress response, the Cpx twocomponent system, has been associated with the regulation of the MdtABC transporter in E. coli [27]. In order to analyze whether $\mathrm{CpxR}$ is involved in the expression of the RND-type pumps MdtABC and MdtUVW in $E$. amylovora Ea1189, we tested whether CpxR is able to bind to the promoter regions of the transporter genes (Figure 2). Our data suggest that CpxR does not directly interact with the promoter regions of $m d t A B C$ and $m d t U V W$. Moreover, overexpression of $\mathrm{CpxR}$ did not induce the expression of the RND pumps MdtABC and MdtUVW (Table 3).

We could demonstrate that flavonoids are natural substrates of the MdtABC and MdtUVW transporter from E. amylovora. The expression of these transporters was induced during infection of apple rootstock. Condensed tannins (polymers of flavanol units found in virtually all parts of a plant) induced the expression of the twocomponent system BaeSR which directly regulates the expression of the MdtABC pump in E. amylovora. Several flavonoids have been reported to possess antibacterial activities [42,43]. Their direct antibacterial activity may be attributable to different mechanisms including inhibition of nucleic acid synthesis, damage of cytoplasmic membrane function, inhibition of energy metabolism, inhibition of cell wall synthesis and inhibition of membrane synthesis $[43,44]$. Flavonoids cause stresses to the bacterial envelope. Therefore, it is not surprising that tannins induce the envelope stress response BaeSR in E. amylovora. 


\section{Conclusions}

The aim of the present study was the characterization of the RND-type multidrug efflux pumps MdtABC and MdtUVW from the plant pathogen E. amylovora, causing fire blight disease of apple, pear, and other members of the Rosaceae family. Our results suggest that MdtABC and MdtUVW play a role in survival and multiplication of E. amylovora in apple rootstocks as well as in the cell envelope stress response of the plant pathogen. The expression of both operons encoding these RND pumps was up-regulated in planta. We could identify the plant polyphenol tannin as inducer of $m d t A B C$ expression. The $m d t A B C$ - and $m d t U V W$-deficient mutants reached lower population sizes than the wild type in apple rootstock suggesting a role of the efflux pumps in resistance towards antimicrobial plant compounds, such as flavonoids. Moreover, we were able to demonstrate that the expression of $m d t A B C$ is activated by the two-component system BaeSR which is involved in the regulation of cell envelope stress responses.

\section{Methods}

Bacterial strains, plasmids and growth conditions

Bacterial strains used in the study are listed in Table 5 and plasmids in Additional file 4. E. amylovora strains were cultured at $28^{\circ} \mathrm{C}$ in Lysogeny Broth (LB) or double Yeast Trypton (dYT). E. coli XL-1 Blue was used as cloning host. DH5 $\alpha \lambda$-pir was used as host for the replacement vectors. BL21(DE3) was used as host for protein overexpression experiments. E. coli cells were routinely maintained at $37^{\circ} \mathrm{C}$

Table 5 Bacterial strains used in this study

\begin{tabular}{|c|c|c|}
\hline Strain & $\begin{array}{l}\text { Relevant characteristics } \\
\text { or genotype }^{a}\end{array}$ & $\begin{array}{l}\text { Reference or } \\
\text { source }\end{array}$ \\
\hline \multicolumn{3}{|l|}{ Escherichia coli } \\
\hline XL1-Blue & $\begin{array}{l}\text { recA1 endA1 gyrA96 thi-1 } \\
\left.\text { hsdR17( } \mathrm{r}_{\mathrm{K}}^{-} \mathrm{m}_{\mathrm{K}}^{+}\right) \text {supE44 relA1 } \\
\text { lac }\left[\mathrm{F}^{\prime} \text { proAB lacl }{ }^{q} \mathrm{Z} \Delta \mathrm{M} 15 \operatorname{Tin} 10\left(\mathrm{TC}^{r}\right)\right]\end{array}$ & Stratagene \\
\hline BL21(DE3) & $\begin{array}{l}\mathrm{F}^{-} \text {ompt gal dcm lon hsdS } \mathrm{B}_{\mathrm{B}}\left(\mathrm{r}_{\mathrm{B}}^{-} \mathrm{m}_{\mathrm{B}}^{-}\right) \\
\lambda(\mathrm{DE} 3)\end{array}$ & Novagen \\
\hline S17-1 & $\begin{array}{l}\text { Tc' Sm }{ }^{r} \text {, recA pro hsdR } \\
\text { (RP4-2-Tc::Mu-Km::Tn7) }\end{array}$ & [45] \\
\hline S17-1 $\lambda$-pir & $\lambda$ pir phage lysogen of S17-1 & [45] \\
\hline DH5a $\lambda$-pir & $\begin{array}{l}\mathrm{F}^{-} \text {supE44 } \Delta / a c \cup 169(\Phi / a c Z \Delta M 15) \\
\left.\text { recA1 endA1 hsdR17( } r_{\mathrm{K}}^{-} \mathrm{m}_{\mathrm{K}}^{+}\right) \text {thi-1 } \\
\text { gyrA96 relA1, } \lambda \text { pir phage lysogen }\end{array}$ & D. Lies, Caltech \\
\hline \multicolumn{3}{|l|}{ Erwinia amylovora } \\
\hline Ea1189 & wild type & $\mathrm{GSPB}^{b}$ \\
\hline Ea1189-3 & Ea1189, $\mathrm{Km}^{\mathrm{r}}$ cassette in $\mathrm{acrB}$ & {$[7]$} \\
\hline Ea1 189. $\Delta \mathrm{mdt} A B C$ & Ea1189, mdtABC deletion mutant & This study \\
\hline 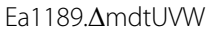 & Ea1189, mdtUVW deletion mutant & This study \\
\hline
\end{tabular}

${ }^{a}$ Antibiotic resistance: $\mathrm{Ap}^{\mathrm{r}}$, ampicillin; $\mathrm{Cm}^{\mathrm{r}}$, chloramphenicol; $\mathrm{Km}^{\mathrm{r}}$, kanamycin; $\mathrm{Sm}^{r}$, streptomycin; $\mathrm{TC}^{r}$, tetracycline.

${ }^{b} \mathrm{GSPB}$, Göttinger Sammlung Phytopathogener Bakterien, Göttingen, Germany. in $\mathrm{dYT}$ medium. Cultures harboring individual vectors were supplemented with $50 \mu \mathrm{g} / \mathrm{ml}$ ampicillin (Ap) for $E$. coli or $250 \mu \mathrm{g} / \mathrm{ml}$ for E. amylovora, $25 \mu \mathrm{g} / \mathrm{ml}$ chloramphenicol $(\mathrm{Cm}), 2 \mu \mathrm{g} / \mathrm{ml}$ gentamicin $(\mathrm{Gm})$ or $25 \mu \mathrm{g} / \mathrm{ml}$ kanamycin $(\mathrm{Km})$ when necessary. Bacterial growth was monitored using a spectrophotometer at $600 \mathrm{~nm}\left(\mathrm{OD}_{600}\right)$.

PCR amplifications, modifications and protein purification PCR primers are listed in Additional file 9. Primers were designed based on the genome sequence of E. amylovora CFBP1430 available from NCBI (NC_013961.1). Screening PCR reactions were carried out using DreamTaq DNA polymerase (Thermo Scientific) in accordance with the manufacturer's instructions. Annealing temperatures were optimized based on the melting temperatures of the respective primers. For high fidelity PCR reactions, Phusion DNA polymerase (Thermo Scientific) or Q5 DNA polymerase (NEB) was used.

Restriction enzyme (Thermo Scientific) and T4 DNA ligase (Thermo Scientific) reactions were performed following the manufacturer's instructions at the appropriate temperature where all ligation reactions were incubated at room temperature.

DNA purifications were either performed using the GeneJET PCR purification kit (Thermo Scientific) or the GeneJET Gel extraction kit (Thermo Scientific) according to the manufacturer's instructions.

\section{Construction of $m d t A B C$ - and mdtUVW-deficient mutants of E. amylovora}

The construction of the knockout vectors was based on the protocol described by Zumaquero et al. [46]. Briefly, approximately 500 to $700 \mathrm{bp}$ flanking the 5 ' and 3' regions of the ORF's to be deleted were PCR-amplified using primer pairs mdtABC-A1 and mdtABC-A2, mdtABC-B1 and mdtABC-B2, mdtUVW-A1 and mdtUVW-A2, mdtU VW-B1 and mdtUVW-B2. Primers A2 and B1 share a 20nucleotide homologous sequence at their 5 ' ends, consisting of the T7 primer sequence and a KpnI restriction site [46]. After amplification, the obtained fragments were gelpurified and approximately $40 \mathrm{ng}$ of an A and B fragment were used for a fusion PCR reaction with primers A1 and B2. The resulting fusion product was gel-purified, cloned into pJET1.2 and confirmed by sequencing. Next, a chloramphenicol cassette, flanked by Flp-FRT sites, was cut from plasmid $\mathrm{pFCm} 1$ and subsequently inserted into the KpnI-digested pJET constructs. The deletion alleles were cut with EcoRI and further ligated into EcoRIdigested pCAM-Km, yielding the final replacement plasmids pCAM-Km.mdtABC-Cm and pCAM-Km.mdtUV $\mathrm{W}-\mathrm{Cm}$. The plasmids were transformed into electrocompetent cells of $E$. amylovora Ea1189, which subsequently were grown for $3 \mathrm{~h}$ at $28^{\circ} \mathrm{C}$ in dYT broth. Putative mutants were screened for homologous recombination events 
by testing their antibiotic resistance. Mutants that resulted from single crossover events were identified by their ability to grow on plates containing $\mathrm{Km}$. In order to confirm gene deletion through a double crossover event in Cmresistant and $\mathrm{Km}$-sensitive colonies, primers which bind upstream and downstream of the A and B fragment used for generation of the gene replacement vector were designed. PCRs were done using these locus-specific primers with outward-facing primers binding within the $\mathrm{Cm}$ cassette. Amplified PCR products were verified by sequencing.

The Cm-FRT cassette was finally excised using the temperature-sensitive plasmid $\mathrm{pCP} 20$ that carries the yeast Flp recombinase gene $[47,48]$. Briefly, Cm-resistant mutants of Ea1189 were transformed with pCP20 and selected at $28^{\circ} \mathrm{C}$ on LB plates containing Ap. Subsequently, Ap-resistant transformants were streaked on non-selective agar plates and incubated at $43^{\circ} \mathrm{C}$ for $1 \mathrm{~h}$, following incubation at $28^{\circ} \mathrm{C}$ for 48 to $60 \mathrm{~h}$. Single colonies were selected and tested on agar plates containing $\mathrm{Cm}$ or Ap to confirm successful excision of the $\mathrm{Cm}$ cassette and loss of plasmid pCP20.

\section{Cloning of the $m d t A B C$ and $m d t U V W$ regions of $E$. amylovora}

The $m d t A B C$ and $m d t U V W$ operons, including their promoter regions, were $\mathrm{PCR}$-amplified using the primer pairs mdtABC_P_SacI/mdtABC_ApaI (7702 bp) and mdtUVW_P_SacI/mdtUVW_ApaI (7810 bp), respectively. The obtained PCR products were sequenced and subsequently cloned into SacI-ApaI-digested pBlueScript II KS(+) to obtain expression from the native promoters (pBlueKS.mdtABC-ext, pBlueKS.mdtUVW-ext) or into pBlueScript II $\mathrm{SK}(+)$ to obtain expression from the native promoters and $\mathrm{P}_{\text {lac }}$ (pBlueSK.mdtABC-ext, pBlueSK.mdtUVW-ext).

In order to study the effect of $\beta$-lactam antibiotics on growth of $E$. amylovora containing $m d t A B C$ and $m d t U V W$ overexpression plasmids, the $m d t A B C$ and $m d t U V W$ regions were cloned into pBlueScript II KS vectors where the $\mathrm{Ap}^{\mathrm{r}}$ gene was exchanged by a $\mathrm{Sm}^{\mathrm{r}}$ gene (Additional file 4).

\section{Drug susceptibility tests}

The minimal inhibitory concentrations (MICs) of drugs for $E$. amylovora strains were determined by a 2 -fold dilution assay in a 96-well plate using Mueller-Hinton broth (MHB). All tests were performed at least in triplicate following the Clinical and Laboratory Standards Institute recommendations [49]. Growth of bacteria at $28^{\circ} \mathrm{C}$ was examined by visual inspection after $48 \mathrm{~h}$ incubation. The MIC was defined as the lowest concentration of an antibiotic that completely prevented visible cell growth.

\section{Generation of promoter-egfp fusion constructs}

Transcriptional fusions between the promoter regions of $m d t A B C$ and $m d t U V W$, respectively, and egfp were created using a previously described PCR-based method [50]. Briefly, a 294-bp fragment containing the upstream region of $m d t A B C$ was amplified using the primer mdtABC_up and the reverse primer mdtABC-P-egfp containing a 24-nt extension homologous to the start of the egfp gene. The mdtUVW upstream region (266 bp) was amplified using the primer mdtUVW_up and the reverse primer mdtUVW-P-egfp. Next, a 916-bp fragment containing the reporter gene egfp was amplified using the primer pair egfp-ATG and egfp-Cm and the plasmid pBBR.egfp.TIR as template [7]. All PCR products were gel-purified and validated by sequencing. For the fusion reaction, $60 \mathrm{ng}$ of a PCR fragment containing a promoter region were mixed with $20 \mathrm{ng}$ of the reporter gene fragment. For fusion of the $m d t A B C$ promoter to the egfp gene, the primers mdtABC-P_SacII and uidA-t0-KpnI were used. The primers mdtUVW-P_SacII and uidA-t0-KpnI were used in a PCR to fuse the $m d t U V W$ promoter to egfp. The fusion products were gel-purified and cloned into SacIIKpnI-treated pBBR1MCS, in opposite direction to the lacZ promoter, yielding plasmids pBBR.mdtABC-Pro. egfp and pBBR.mdtUVW-Pro.egfp.

\section{Promoter activity of $m d t A B C$ and $m d t U V W$ in vitro}

The reporter gene egfp was employed to study the impact of diverse antimicrobial substances on promoter activities of $m d t A B C$ and $m d t U V W$ in E. amylovora. Plasmids carrying the transcriptional fusions were transformed into Ea1189. Antimicrobial compounds were added to the bacterial cells in 96-well microtiter plates by the 2-fold dilution method as described for MIC assays. EGFP fluorescence of the cells following exposure to various concentrations of the substrates was measured 48 hours after incubation at $28^{\circ} \mathrm{C}$ using the microplate reader Infinite M1000 PRO (Tecan, Crailsheim, Germany) with an excitation wavelength of $470 \mathrm{~nm}$ and emission detection at $516 \mathrm{~nm}$.

Fluorescence values obtained were plotted versus optical densities in a scatter plot. A best-fit linear regression line was added to the plot and a 95\% confidence interval determined using the software package for the $\mathrm{R}$ statistical language and environment [51]. Data points that did not meet the confidence interval criteria indicate fluorescence values higher than the average, thereby suggesting promoter induction by the respective compound. The following substrates were applied to this assay: (+)-catechin, acridine orange, acriflavine, amikacin, azithromycin, benzalkonium chloride, berberine, bile salts, cadmium acetate, chloramphenicol, ciprofloxacin, clarithromycin, clotrimazole, cobalt chloride, copper sulfate, crystal violet, daidzein, deoxycholate, erythromycin, 
ethidium bromide, fusaric acid, fusidic acid, genistein, gentamicin, josamycin, luteolin, myricetin, naladixic acid, naringenin, nickel chloride, nitrofurantoin, norfloxacin, novobiocin, orobol, phloretin, polymyxin B, quercitin, rhodamine 6G, rifampicin, roxithromycin, SDS, silver nitrate, sodium arsenate, sodium tungstate, streptomycin, tetracycline, tetraphenylphosphonium chloride, tobramycin and zinc sulfate.

\section{Plant material and inoculation procedures}

Apple plants (rootstock Malus MM106) were grown in a greenhouse at 20 to $25^{\circ} \mathrm{C}, 60 \%$ humidity, and $12 \mathrm{~h}$ photoperiod $(15,000 \mathrm{~lx})$. E. amylovora strains grown on LB agar for $24 \mathrm{~h}$, were resuspended and diluted to an $\mathrm{OD}_{600}$ of 1.0 in sterile demineralized water. Apple plants were inoculated by prick technique [52]. Each bacterial strain was inoculated into one shoot of minimum five single plants. A bacterial suspension $(5 \mu \mathrm{l})$ was placed onto each wound on the shoot tip. Plants were monitored for symptom development daily. Survival of bacteria in plant tissue was examined by re-isolation of bacterial cells 1,3 and 7 day(s) after inoculation, respectively, from $1 \mathrm{~cm}$ of the shoot tip around the inoculation area. The experiment was repeated at least three times.

In order to analyze the abundance of $m d t A$ and $m d t U$ mRNA transcripts in E. amylovora Ea1189 during growth in apple rootstock MM106, total RNA was isolated from infected apple shoots 1, 3 and 7 day(s) post inoculation, respectively. Five individual wounds were pooled together, homogenized in sterile water and centrifuged for $2 \mathrm{~min}$ at $4000 \mathrm{rpm}$. The supernatant was transferred to $15 \mathrm{ml}$ killing buffer (20 mM Tris-HCl, pH 7.5; $20 \mathrm{mM} \mathrm{NaN}_{3}$ ) [53] and centrifuged for $20 \mathrm{~min}$ at $4000 \mathrm{rpm}$. The supernatant was decanted and the pellet frozen at $-80^{\circ} \mathrm{C}$ for further RNA extraction.

\section{Virulence assay on immature pears}

Virulence of E. amylovora Ea1189 and the mdtABC, $m d t U V W$, baeR and $c p x R$ mutants was determined on immature pears (Pyrus communis L. cv. 'Bartlett'). Bacteria, grown on LB agar plates at $28^{\circ} \mathrm{C}$ for $24 \mathrm{~h}$, were resuspended and adjusted to an $\mathrm{OD}_{600}$ of 1.0 in sterile demineralized water for inoculation. Immature pear fruits were surface-sterilized and pricked with a sterile needle as described previously [54]. Wounds were inoculated with $5 \times 10^{6} \mathrm{CFU} / \mathrm{ml}$ and incubated in a humidified chamber at $18^{\circ} \mathrm{C}$ and $28^{\circ} \mathrm{C}$, respectively for 6 to 14 days. Disease symptoms were visually recorded by means of necrosis surrounding the infection site. Five fruits were assayed and the experiment was repeated twice.

To analyze gene expression of E. amylovora Ea1189 during growth on pear fruits, immature fruits were cut in slices (approx. $0.5 \mathrm{~cm}$ ). Five slices were inoculated with $100 \mu \mathrm{l}$ of a bacterial suspension adjusted to an $\mathrm{OD}_{600}$ of
1.0 in sterile demineralized water. The suspension was evenly distributed on the slice and incubated for 12 hours in a humidified chamber at room temperature. Next, the upper layer of the surface was scratched from the five slices, resuspended in $25 \mathrm{ml}$ of PBS and centrifuged for $2 \mathrm{~min}$ at $4000 \mathrm{rpm}$. The supernatant was transferred to $15 \mathrm{ml}$ killing buffer and further processed as described above.

\section{RNA isolation and quantitative RT-PCR}

Cell cultures were grown in LB broth until the desired optical densities was reached. An aliquot containing $15 \times 10^{9} \mathrm{CFU}$ (equivalent of $15 \mathrm{ml}$ culture with an $\mathrm{OD}_{600}$ of 1.0) was transferred to $15 \mathrm{ml}$ killing buffer and centrifuged for $20 \mathrm{~min}$ at $4000 \mathrm{rpm}$. The supernatant was decanted and the pellet frozen at $-80^{\circ} \mathrm{C}$ for further RNA extraction.

Total RNA was isolated by acid phenol/chloroform extraction [53]. The obtained RNA was DNAse (Ambion/ Life Technologies) treated and subsequently checked for purity by gel electrophoresis and determination of the $\mathrm{A}_{260} / \mathrm{A}_{280}$ and $\mathrm{A}_{260} / \mathrm{A}_{230}$ ratios using a Nanodrop ND2000 spectrophotometer (Thermo Fischer Scientific). High quality RNA was reverse transcribed and amplified with the OneStep RT-PCR Kit according to the manufacturer's protocol (Qiagen). Template RNA (5 ng) was used in a standard 25- $\mu$ l qRT-PCR reaction with specific primers (Additional file 5). As control, RNA samples without reverse transcriptase were included to detect possible DNA contaminations.

For analysis, a Mastercycler ep realplex ${ }^{2}$ gradient $\mathrm{S}$ (Eppendorf, Hamburg, Germany) was used. Cycling parameters included a $15 \mathrm{~min}$ initial denaturation at $95^{\circ} \mathrm{C}$ to activate the DNA polymerase followed by 40 cycles consisting of $15 \mathrm{sec}$ at $95^{\circ} \mathrm{C}, 30 \mathrm{sec}$ at $55^{\circ} \mathrm{C}$ and $30 \mathrm{sec}$ at $72^{\circ} \mathrm{C}$. The final step consisted of $1 \mathrm{~min}$ at $95^{\circ} \mathrm{C}$ and $30 \mathrm{sec}$ at $55^{\circ} \mathrm{C}$. A melting curve analysis with a temperature ramp from $25^{\circ} \mathrm{C}$ to $95^{\circ} \mathrm{C}$ in 20 min was performed at the end of each run to determine specificity of amplified qPCR products.

Each sample was analyzed for gene expression in triplicate. Quantification of mRNA transcripts was performed by the comparative $C_{t}$ method. Briefly, the $C_{t}$ values of the samples of interest were compared with a non-treated sample. All $\mathrm{C}_{\mathrm{t}}$ values were normalized to the housekeeping gene $\operatorname{rec} A$, which shows constant expression at different ODs and medium compositions as well as similar amplification efficiency to the target genes $[34,55]$. The comparative $C_{t}$ method was calculated by $2^{-\left(\Delta C_{t}, \text { sample }-\Delta C_{t} \text {,reference }\right)}$, where $\Delta \mathrm{C}_{\mathrm{t}}$ was normalized to the endogenous housekeeping gene $\operatorname{rec} A$. Subsequently, fold-changes between the samples were determined based on the calculated $C_{t}$ method. 


\section{Purification of the BaeR and CpxR protein}

Protein purification was carried out using the Ni-NTA Spin Kit (Qiagen) following the manufacturer's instructions. Briefly, E. coli BL21(DE3) harboring the expression plasmid pET28a.baeR or pET28a.cpxR was grown at $37^{\circ} \mathrm{C}$ in $50 \mathrm{ml} \mathrm{LB}$ broth supplemented with kanamycin. When the culture reached an $\mathrm{OD}_{600}$ of 0.6 , IPTG was added to a final concentration of $1 \mathrm{mM}$ and the culture further incubated for 4 hours. Cells were harvested by centrifugation at $4000 \mathrm{rpm}$ for $20 \mathrm{~min}$. The obtained cell pellet was lysed using lysozyme $(1 \mathrm{mg} / \mathrm{ml})$ for 1 hour on ice and then purified on the Ni-NTA spin columns. Lysate, wash fractions and eluted protein samples were collected and further analyzed by SDS-PAGE.

\section{Electrophoretic mobility shift assay}

DNA fragments used for the electrophoretic mobility shift assay (EMSA) were PCR amplified using Cy5-labeled primers to perform a non-radioactive EMSA. DNA fragments used were the upstream region of $m d t A B C$ (290 bp), $m d t U V W$ (276 bp) and as control, a fragment of the tolC gene (248 bp). Approximately $0.3 \mathrm{pmol}$ of Cy5-labeled DNA was mixed with increasing concentrations of Histagged BaeR or CpxR protein in a binding buffer reaction (10 mM Tris-HCl, pH 7.5; $50 \mathrm{mM} \mathrm{KCl;} 5 \mathrm{mM} \mathrm{MgCl}$; $1 \mathrm{mM}$ DTT; $2.5 \%$ glycerol). To decrease unspecific binding, 50 ng competitor DNA (Salmon sperm DNA, AppliChem) was added to the reaction. Incubation was done at room temperature for $30 \mathrm{~min}$. The total reaction was run on a native $4 \%$ polyacrylamide gel in $0.5 \times$ Tris-borate-EDTA (TBE) buffer at constant $25 \mathrm{~mA}$. After electrophoresis, fluorescence signals of the labeled DNA were visualized using a FLA-3000 phosphorimager (Raytest, Straubenhardt, Germany).

\section{Overexpression of the BaeR and CpxR}

To investigate whether overexpression of the response regulators BaeR and CpxR affects expression of the multidrug efflux systems $m d t A B C$ and $m d t U V W$, baeR and $c p \times R$ were cloned into the $\mathrm{pBAD} 24$ vector where gene expression is under control of the arabinose-inducible promoter $\mathrm{P}_{\mathrm{BAD}}$. Hence, baeR was amplified using the primer pairs baeR_SacII/baeR_ApaI and $c p x R$ using cpxR(HindIII)_fwd/cpxR(EcoRI)_rev. The obtained PCR products were sequenced and subsequently cloned into SacII-ApaI-digested pBAD24 (pBAD24.baeR) or HindIII/ EcoRI-digested pBAD24 (pBAD24.cpxR). Next, plasmids were transformed into E. amylovora Ea1189 and protein expression was induced by adding $1 \% \mathrm{~L}$-arabinose when cultures reached an $\mathrm{OD}_{600}$ of 0.5 . Cells were further incubated for 1 hour at $28^{\circ} \mathrm{C}$ and subsequently transferred into killing buffer. Afterwards, cells were harvested by centrifugation for $20 \mathrm{~min}$ at $4000 \mathrm{rpm}$. The supernatant was decanted and the pellet frozen at $-80^{\circ} \mathrm{C}$ for further RNA extraction.

\section{Additional files}

\begin{abstract}
Additional file 1: BLASTP results for MdtABC and MdtUVW from $E$. amylovora Ea1189 and MdtABC from E. coli W3110.

Additional file 2: Modified view of the genomic organization of the $m d t A B C D$ locus from $E$. coli MG1655 and the $m d t A B C$ locus from $E$. amylovora CFBP1430. Visualization was obtained by the Artemis

Comparison Tool [56]. The dark areas indicate homologous regions with a minimum identity cutoff score of $50 \%$ and a maximum identity cutoff score of $89 \%$. The alignment was performed using the nucleotide search BLASTN from NCBI.
\end{abstract}

Additional file 3: Transmembrane protein topology of (A) MdtABC from $E$. amylovora Ea1189, (B) MdtUVW from $E$. amylovora Ea1189 and (C) MdtABC from E. coli W3110. The upper line indicates the

predicted topology from TOPCONS [31] based on amino acid sequences. Red lines indicate an inner membrane orientation; blue lines indicate an outer membrane orientation. Grey boxes indicate transmembrane helices spanning from the inside to the outside, white boxes indicate transmembrane helices spanning from the outside to the inside. Below the line is a graphical interpretation of the reliability of the prediction for each amino acid.

Additional file 4: Plasmids used in this study.

Additional file 5: Promoter activities of $m d t A B C$ and $m d t U V W$ from E. amylovora Ea1189 determined in the course of growth. (A) Relative mRNA transcript abundance of $m d t A B C$ and $m d t U W W$ during cellular growth of Ea1189 as determined by quantitative RT-PCR. The relative mRNA level was related to the highest mean value determined for a gene, which was defined as $100 \%$. (B) Expression of $m d t A B C$ and mdtUWW as determined by transcriptional fusions with the reporter gene egfp. E. amylovora wild type was transformed with pBBR.mdtABC-Pro.egfp and pBBR.UWW-Pro.egfp, respectively. To assay fluorescence of the enhanced green fluorescent protein during growth of cells in LB broth, aliquots were harvested at distinct optical densities and adjusted to an $\mathrm{OD}_{600}$ value of 0.1 . Experiments were performed in triplicates with similar results. $\mathrm{OD}_{600}$, optical density at $600 \mathrm{~nm}$.

Additional file 6: Sequence alignment of the amino acid sequences of (A) BaeR from E. amylovora Ea1189 and E. coli W3110 (YP_490321.1) and (B) CpxR from E. amylovora Ea1189 and E. coli W3110 (YP_491538.1). Analysis was performed with Clustal Omega and Jalview $[28,57]$. BaeR of Ea1189 is $74 \%$ identical to BaeR of E. coli. CpxR of Ea1189 is $90 \%$ identical to CpxR of E. coli. Identical amino acid residues are shown in blue. Yellow bars show a quantitative measurement of conserved physico-chemical properties where the highest score shows amino acids of the same physico-chemical class. Black bars indicate predicted response regulator receiver domains and grey bars indicate predicted transcriptional regulatory domains from E. amylovora Ea1189 as determined by using PFAM [58].

Additional file 7: Virulence assay on apple rootstock MM106.

Additional file 8: Symptoms of E. amylovora Ea1189 and $a c r B$, $\triangle m d t A B C$ and $\triangle m d t U V W$ mutants in immature pear at (A) $18^{\circ} \mathrm{C}$, 14 days post inoculation and $(B) 28^{\circ} \mathrm{C}, 6$ days post inoculation. Pictures represent one out of ten pear fruits per infection.

Additional file 9: Primers used in this study.

\section{Competing interests}

The authors declared that they have no competing interests.

\section{Authors' contributions}

DP carried out the molecular work, participated in the bioinformatical analysis and drafted the manuscript. HW conceived of the study, participated in its design and coordination and helped to draft the manuscript. All authors read and approved the final manuscript. 


\section{Acknowledgments}

This study was supported by Jacobs University Bremen and by the MOLIFE Research Center, Jacobs University Bremen. Furthermore, we acknowledge Yvonne Braun for critical reading of the manuscript.

Received: 9 May 2014 Accepted: 3 July 2014

Published: 11 July 2014

\section{References}

1. Vanneste J: Fire blight: The disease and its causative agent, Erwinia amylovora. Oxon, UK: CABI Publishing; 2000.

2. Nicholson RL, Hammerschmidt R: Phenolic compounds and their role in disease resistance. Annu Rev Phytopathol 1992, 30:369-389.

3. Zgurskaya HI, Krishnamoorthy G, Tikhonova EB, Lau SY, Stratton KL: Mechanism of antibiotic efflux in Gram-negative bacteria. Front Biosci 2003, 8:s862-873.

4. Piddock LJ: Clinically relevant chromosomally encoded multidrug resistance efflux pumps in bacteria. Clin Microbiol Rev 2006, 19:382-402.

5. Nikaido H: Multidrug efflux pumps of gram-negative bacteria. J Bacteriol 1996, 178:5853-5859.

6. Walsh C: Molecular mechanisms that confer antibacterial drug resistance. Nature 2000, 406:775-781.

7. Burse $A$, Weingart $H$, Ullrich MS: The phytoalexin-inducible multidrug efflux pump AcrAB contributes to virulence in the fire blight pathogen, Erwinia amylovora. Mol Plant-Microbe Interact 2004, 17:43-54.

8. Murakami S, Nakashima R, Yamashita E, Yamaguchi A: Crystal structure of bacterial multidrug efflux transporter AcrB. Nature 2002, 419:587-593.

9. Zgurskaya $\mathrm{HI}$, Nikaido $\mathrm{H}$ : Bypassing the periplasm: reconstitution of the AcrAB multidrug efflux pump of Escherichia coli. Proc Natl Acad Sci U S A 1999, 96:7190-7195.

10. Seeger MA, von Ballmoos C, Eicher T, Brandstatter L, Verrey F, Diederichs $K$ Pos KM: Engineered disulfide bonds support the functional rotation mechanism of multidrug efflux pump AcrB. Nat Struct Mol Biol 2008, 15:199-205.

11. Kim HS, Nagore D, Nikaido $\mathrm{H}$ : Multidrug efflux pump MdtBC of Escherichia coli is active only as a $B_{2} C$ heterotrimer. J Bacteriol 2010, 192:1377-1386.

12. Kim HS, Nikaido $H$ : Different functions of $M d t B$ and $M d t C$ subunits in the heterotrimeric efflux transporter $\mathrm{MdtB}_{2} \mathrm{C}$ complex of Escherichia coli. Biochemistry 2012, 51:4188-4197.

13. Nagakubo S, Nishino K, Hirata T, Yamaguchi A: The putative response regulator BaeR stimulates multidrug resistance of Escherichia coli via a novel multidrug exporter system, MdtABC. J Bacterio/ 2002, 184:4161-4167.

14. Baranova N, Nikaido $\mathrm{H}$ : The baeSR two-component regulatory system activates transcription of the yegMNOB ( $m d t A B C D$ ) transporter gene cluster in Escherichia coli and increases its resistance to novobiocin and deoxycholate. J Bacteriol 2002, 184:4168-4176.

15. Nishino K, Nikaido E, Yamaguchi A: Regulation of multidrug efflux systems involved in multidrug and metal resistance of Salmonella enterica serovar Typhimurium. J Bacteriol 2007, 189:9066-9075.

16. Wang D, Fierke CA: The BaeSR regulon is involved in defense against zinc toxicity in E. coli. Metallomics 2013, 5:372-383.

17. Appia-Ayme C, Patrick E, Sullivan MJ, Alston MJ, Field SJ, AbuOun M, Anjum MF, Rowley G: Novel inducers of the envelope stress response BaeSR in Salmonella Typhimurium: BaeR is critically required for tungstate waste disposal. PLoS One 2011, 6:e23713.

18. Raffa RG, Raivio TL: A third envelope stress signal transduction pathway in Escherichia coli. Mol Microbiol 2002, 45:1599-1611.

19. Leblanc SK, Oates CW, Raivio TL: Characterization of the induction and cellular role of the BaeSR two-component envelope stress response of Escherichia coli. J Bacteriol 2011, 193:3367-3375.

20. Zoetendal EG, Smith AH, Sundset MA, Mackie Rl: The BaeSR two-component regulatory system mediates resistance to condensed tannins in Escherichia coli. Appl Environ Microbiol 2008, 74:535-539.

21. Price NL, Raivio TL: Characterization of the Cpx regulon in Escherichia coli strain MC4100. J Bacteriol 2009, 191:1798-1815.

22. Raivio TL, Silhavy TJ: Periplasmic stress and ECF sigma factors. Annu Rev Microbiol 2001, 55:591-624.

23. Vogt SL, Raivio TL: Just scratching the surface: an expanding view of the Cpx envelope stress response. FEMS Microbiol Lett 2012, 326:2-11.
24. Raivio TL, Popkin DL, Silhavy TJ: The Cpx envelope stress response is controlled by amplification and feedback inhibition. J Bacterio/ 1999, 181:5263-5272.

25. Otto K, Silhavy TJ: Surface sensing and adhesion of Escherichia coli controlled by the Cpx-signaling pathway. Proc Natl Acad Sci U S A 2002, 99:2287-2292.

26. Hirakawa H, Nishino K, Hirata T, Yamaguchi A: Comprehensive studies of drug resistance mediated by overexpression of response regulators of two-component signal transduction systems in Escherichia coli. J Bacteriol 2003, 185:1851-1856.

27. Hirakawa H, Inazumi Y, Masaki T, Hirata T, Yamaguchi A: Indole induces the expression of multidrug exporter genes in Escherichia coli. Mol Microbiol 2005, 55:1113-1126.

28. Sievers F, Wilm A, Dineen D, Gibson TJ, Karplus K, Li W, Lopez R, McWilliam H, Remmert M, Söding J, Thompson JD, Higgins DG: Fast, scalable generation of high-quality protein multiple sequence alignments using Clustal Omega. Mol Syst Biol 2011, 7:539.

29. Gonnet GH, Hallett MT, Korostensky C, Bernardin L: Darwin v. 2.0: an interpreted computer language for the biosciences. Bioinformatics 2000, 16:101-103

30. Frawley ER, Crouch ML, Bingham-Ramos LK, Robbins HF, Wang W, Wright GD, Fang FC: Iron and citrate export by a major facilitator superfamily pump regulates metabolism and stress resistance in Salmonella Typhimurium. Proc Natl Acad Sci U S A 2013, 110:12054-12059.

31. Bernsel $A$, Viklund $H$, Hennerdal A, Elofsson A: TOPCONS: consensus prediction of membrane protein topology. Nucleic Acids Res 2009, 37:W465-468.

32. Saier MH Jr, Tam R, Reizer A, Reizer J: Two novel families of bacterial membrane proteins concerned with nodulation, cell division and transport. Mol Microbiol 1994, 11:841-847.

33. Paulsen IT, Brown MH, Skurray RA: Proton-dependent multidrug efflux systems. Microbiol Rev 1996, 60:575-608.

34. Pletzer $D$, Weingart $H$ : Characterization of AcrD, a resistance-nodulation-cell division-type multidrug efflux pump from the fire blight pathogen Erwinia amylovora. BMC Microbiol 2014, 14:13.

35. Murakami S, Nakashima R, Yamashita E, Matsumoto T, Yamaguchi A: Crystal structures of a multidrug transporter reveal a functionally rotating mechanism. Nature 2006, 443:173-179.

36. Nishino K, Latifi T, Groisman EA: Virulence and drug resistance roles of multidrug efflux systems of Salmonella enterica serovar Typhimurium. Mol Microbiol 2006, 59:126-141.

37. Treutter D: Significance of flavonoids in plant resistance and enhancement of their biosynthesis. Plant Biol 2005, 7:581-591.

38. Scalbert A: Antimicrobial properties of tannins. Phytochemistry 1991, 30:3875-3883

39. Halbwirth H, Fischer TC, Roemmelt S, Spinelli F, Schlangen K, Peterek S, Sabatini E, Messina C, Speakman JB, Andreotti C, Rademacher W, Bazzi C, Costa G, Treutter D, Forkmann G, Stich K: Induction of antimicrobial 3-deoxyflavonoids in pome fruit trees controls fire blight. Z Naturforsch C 2003, 58:765-770.

40. Schofield P, Mbugua DM, Pell AN: Analysis of condensed tannins: a review. Anim Feed Sci Technol 2001, 91:21-40.

41. Hirakawa $H$, Nishino $K$, Yamada J, Hirata T, Yamaguchi A: $\beta$-lactam resistance modulated by the overexpression of response regulators of two-component signal transduction systems in Escherichia coli. J Antimicrob Chemother 2003, 52:576-582.

42. Xu HX, Lee SF: Activity of plant flavonoids against antibiotic-resistant bacteria. Phytother Res 2001, 15:39-43.

43. Cushnie TP, Lamb AJ: Antimicrobial activity of flavonoids. Int J Antimicrob Agents 2005, 26:343-356.

44. Cushnie TP, Lamb AJ: Recent advances in understanding the antibacterial properties of flavonoids. Int J Antimicrob Agents 2011, 38:99-107.

45. Sambrook J, Russell DW: Molecular cloning: a laboratory manual. Cold Spring Harbor: Cold Spring Harbor Press; 2001.

46. Zumaquero A, Macho AP, Rufián JS, Beuzón CR: Analysis of the role of the type III effector inventory of Pseudomonas syringae pv. phaseolicola 1448a in interaction with the plant. J Bacterio/ 2010, 192:4474-4488.

47. Hoang T, Karkhoff-Schweizer RR, Kutchma AJ, Schweizer HP: A broad-host-range Flp-FRT recombination system for site-specific excision of chromosomally-located DNA sequences: application for isolation of unmarked Pseudomonas aeruginosa mutants. Gene 1998, 212:77-86. 
48. Cherepanov PP, Wackernagel W: Gene disruption in Escherichia coli: $\mathrm{Tc}^{\mathrm{R}}$ and $\mathrm{Km}^{\mathrm{R}}$ cassettes with the option of Flp-catalyzed excision of the antibiotic-resistance determinant. Gene 1995, 158:9-14.

49. Clinical and Laboratory Standards Institute: Methods for dilution antimicrobial susceptibility tests for bacteria that grow aerobically. Approved standard. 9th edition. Wayne, PA: CLSI document M7-A7; 2012.

50. Hobert O: PCR fusion-based approach to create reporter gene constructs for expression analysis in transgenic C. elegans. Biotechniques 2002, 32:728-730

51. Hornik K: R: A language and environment for statistical computing. Vienna, Austria: R Foundation for Statistical Computing; 2013.

52. May R, Völksch B, Kampmann G: Antagonistic activities of epiphytic bacteria from soybean leaves against Pseudomonas syringae pv. glycinea in vitro and in planta. Microb Ecol 1997, 34:118-124.

53. Schenk $A$, Weingart $H$, Ullrich MS: Extraction of high-quality bacterial RNA from infected leaf tissue for bacterial in planta gene expression analysis by multiplexed fluorescent Northern hybridization. Mol Plant Pathol 2008, 9:227-235.

54. McGhee GC, Jones AL: Complete nucleotide sequence of ubiquitous plasmid pEA29 from Erwinia amylovora strain Ea88: gene organization and intraspecies variation. Appl Environ Microbiol 2000, 66:4897-4907.

55. Takle GW, Toth IK, Brurberg MB: Evaluation of reference genes for real-time RT-PCR expression studies in the plant pathogen Pectobacterium atrosepticum. BMC Plant Biol 2007, 7:50.

56. Rutherford K, Parkhill J, Crook J, Horsnell T, Rice P, Rajandream MA, Barrell B: Artemis: sequence visualization and annotation. Bioinformatics 2000, 16:944-945.

57. Waterhouse AM, Procter JB, Martin DM, Clamp M, Barton GJ: Jalview Version 2 - a multiple sequence alignment editor and analysis workbench. Bioinformatics 2009, 25:1189-1191.

58. Punta M, Coggill PC, Eberhardt RY, Mistry J, Tate J, Boursnell C, Pang N, Forslund K, Ceric G, Clements J, Heger A, Holm L, Sonnhammer EL, Eddy SR, Bateman A, Finn RD: The Pfam protein families database. Nucleic Acids Res 2012, 40:D290-301.

doi:10.1186/1471-2180-14-185

Cite this article as: Pletzer and Weingart: Characterization and regulation of the Resistance-Nodulation-Cell Division-type multidrug efflux pumps MdtABC and MdtUVW from the fire blight pathogen Erwinia amylovora. BMC Microbiology 2014 14:185.

\section{Submit your next manuscript to BioMed Central and take full advantage of:}

- Convenient online submission

- Thorough peer review

- No space constraints or color figure charges

- Immediate publication on acceptance

- Inclusion in PubMed, CAS, Scopus and Google Scholar

- Research which is freely available for redistribution 